\title{
THE CONCEPTION OF THOUGHT AS A CYCLIC PROCESS.
}

66 THE eye is the first circle," wrote Emerson, "the 1 horizon which it forms is the second; and throughout nature this primary figure is repeated without end."' Nature both draws circles and sends events round in them. There is a crescendo of recurrent cycles: from the rhythmic pulse, rapidly beating out the life of man, to the majestic period of 26,000 years which returns the wobbling pole of the earth to its original position. Recurrent rounds of repetitive change court notice by their frequency and impressiveness. The heart beats; tides rise and fall; sleep alternates with waking; moons wax and wane; egg comes from bird and bird from egg; the seasons return in order. To think of these as minor cycles in one great round of cyclic cosmic change, like day and night within the wider circle of the seasons, was natural, perhaps inevitable. An assembly of widening cycles, from the rapid pulse to the procession of the seasons, easily suggests a vaster, more eternal round that includes them all and constantly returns all change to its starting-point. A knowledge of astronomical recurrent rounds, wider still than the following of spring by spring, would readily open the Greek mind to receive the thought of one vast cosmic cycle. This crescendo of cycles may only partially explain the dominance of the cosmic-cycle conception in early Greek speculation, for, unlike the plant which grows from one seed, dominant con-

1 Essay on Circles. 
cepts have more than one origin; but it doubtless had some share in that dominance. Rhythms tempt imagination to create for itself an ecstasy out of one stupendous cosmic cycle. A day in Brahma's life, ran the Hindu legend, lasted for 4,320,000 years; his year had 360 such days and his life was Ioo years; then he began a new life. ${ }^{2}$ Imagination thus gratifies its delight in immensity and balks the puzzle. of eternity by making every ending another beginning.

When Thales started Western thought on its long march with a primary conception of one universal substance constantly evolving into all the varied items of the world and being constantly restored from them again, his notion of a recurrent cycle of change continued perpetually to fascinate many minds. Nietzsche, more than 2000 years after, sought an eternity for everything - "the sea will wash it up again." Eternal recurrence, he adds, reconciles the materialistic and Platonic extremes of thought. In an infinite universe, he argued, all combinations are realized an infinite number of times, and between any repetition and its recurrence all other possible combinations recur, because each combination determines the series in the same order. Therefore the universe is in constant circular movement." Modern cosmogenic speculation, after opposing the old Greek notion that the cosmic process is a succession of repetitive rounds, tends to return to it. In the days of Clerk Maxwell the destiny of the universe appeared to be an absolute uniformity of temperature: then the birth of worlds would end and cosmic evolution conclude in all its forms. Many now suspect a constant birth of new worlds, which may continually originate life and evolve it. This view tends to receive the old Greek belief into favor; though it may not reconstruct it with so rigorous a metaphysic as Nietzsche.

Thought has constantly oscillated, in its vision of vast 2 Maeterlinck's Mountain Paths, p. 209. S The Will to Power, Bk. 4, 3. 
universal change, between this infinity of repetitive cosmic rounds and an infinitely advancing series. The same alternatives of circle or trajectory press for favor in other places. Louis Dollo prefers the trajectory or serial conception of life. His principle of the irreversibility of evolution affirms that an organism can never recover a previous state completely, even if it enters once again under conditions identical with those of its past life. This principle applies primarily to the race, though it may apply also to individuals. Birds, for example, cannot recover the teeth which they lost during the Cretaceous Period. A reptile who deserted the earth for the air was probably the ancestor of the birds. By fitting themselves for flight, with all its consequences, the birds were compelled to alter their reptile heritage-acquiring new characters and losing old ones. Among the losses were teeth. One ancient bird, the Odontopteryx, tried to regain them; but, instead of true teeth, which had been ir revocably lost, it could only acquire saw-like points on the sides of its beak and lower jaw. Dollo attempts to rest the principle of the irreversibility of evolution securely on induction by enumerating other failures analogous to the vain effort of Odontopteryx. He also attempts to establish it deductively. A change is produced by definite causes; only precisely inverse causes can reverse the change: unless the causes which lost birds their teeth are inverted, the lost teeth cannot be recovered. Such inversions are so improbable that reversions will not occur and life is essentially irreversible."

The pineal gland seems to have left its past irrevocably behind it. The pineal gland is "a small somewhat conical body, of unknown function, situated behind the third ventricle of the brain, and containing sand-like particles." Descartes suggested that it was the seat of the soul. Mod-

- Branislav Petronievics, "Sur la loi de l'évolution irréversible," Science Progress, Jan., 1919.

'Murray's Dictionary. 
ern guesses at its "unknown function" centered steadily on the surmise that it was either a vestige of a central eye or a futile attempt to develop one. Paleontology has apparently confirmed the vestigial eye theory. The ancient amphibian Sphenodon had a third eye in his middle forehead and some of the great winged lizards had also a central eye. The pineal gland appears to be the dwindled remnant of nature's abortive cyclopean experiment. It has, however, not remained functionless: it has substituted one duty for another. "We have hitherto regarded the pineal gland," said Professor Keith recently, "little bigger than a wheat-grain and buried deeply in the brain, as a mere useless vestige of a median or parietal eye, derived from some distant human ancestor in whom that eye was functional, but on the clinical and experimental evidence now rapidly accumulating we must assign to it a place in the machinery which controls the growth of the body." It acts, apparently, by secreting "morphogenetic hormones" and letting them loose into the circulatory system. These minute circulating substances extend pineal influence to the whole body by stimulating or directing the growth of its various organs. It is incredible, or almost incredible, that the pineal gland should ever travel backward along its original route and restore the third eye of Sphenodon to his descendants. We can be reasonably assured that we shall never suffer the inconvenient and unesthetic possession of an eye in the middle of our foreheads. Dollo's principle of the irreversibility of life seems, here at any rate, to be both certain and welcome. Euclid was fond of insisting that what applied to a particular triangle applied also to other triangles; similarly, we may suppose, that as birds cannot recover their ancestral teeth or we our ancestral central eye, so life in all its physical aspects is estion.

- British Association Addresses, 1919 : Address to the Anthropological Sec- 
sentially irreversible. It seems improbable that life on earth will ever return to the protoplasm from which it probably sprang. If there is a great cosmic cycle it probably does not include within it a minor cycle of life which constantly returns all living things to the primal germinal material from which they first came.

It would still be possible, of course, for successive developments to repeat the history of terrestrial life. If a large, swiftly moving body crashed into the sun a wave of heat would travel to the earth, destroy all life upon it and make of it a ball of fire. When it had cooled it might again bring forth life, which might repeat its present course. One description might serve as one history of many manifestations of life: as it has often happened on other planets, as it proceeds on earth, now, and as it is destined often to occur again. Such repetitions would be from fresh originations: they would not be recurrences in a circuit of change. The same irreversible march of life might constantly begin from countless cosmic centers, though each march were in a straight line that never returned upon itself. If life be really irreversible, man, as he now exists, will not revert to the species which lie behind him on his route. In the biological sphere, in the physiological domain, irreversibility seems to be the law.

Cyclic recurrence, as such, is not logically excluded by irreversibility. The circuit of development might, abstractly considered, circle from proto-life to man and round from man to proto-life again. Irreversibility, abstractly considered, only excludes an oscillation from proto-life to man and back from him, retracing its path, to proto-life again. The evolution of biological species, however, seems to present neither the possibility nor the appearance of cyclic recurrence. Life seems to grow away continually from its base in proto-life, constantly producing new species that do not repeat the old. 
It is less certain that there is no cyclic recurrence in human thought: less certain that throughout thought, as throughout nature, the "primary figure" of the circle is not "repeated without end." It still remains abstractly possible, despite seeming biological irreversibility, that the line from proto-life to man is really an arc, indiscernible as such, of a vast circuit between them. The arc often seems distinctly perceptible, if the circuit itself is not actually completed, in the line of mental movement. "Thoughts and things," wrote James, "are names for two sorts of object, which common sense will always find contrasted and will always practically oppose to each other." Descartes encouraged philosophers to cut this distinction so deeply as to create an apparently insoluble mystery out of the connection between the body, which belongs to the world of things, and the mind, which belongs to the world of thought. There seems to be no possible point of contact between particles with material properties moving in space and the mind which seems to have no spatiality, no weight nor other material property. Greek thought began by making the distinction between thought and thing, between soul and body, without cutting it deeply enough to sever them. Aristotle, reviewing the opinions of his predecessors, remarks that they regarded the soul as "one of the objects which are in motion." Both things and thoughts, soul and body, were composed of corpuscles, of material atoms : they were thus enough alike to be partners. Democritus assigned the more subtle, finer and swifter atoms to the soul to distinguish it from the grosser body and from things. He declared, adds Aristotle, "that those [atoms] which are spherical in shape constitute fire and soul" because "atoms of such configuration are best able to penetrate through everything, and to set other things in mo-

7 Essays in Radical Empiricism, p. 1.

${ }^{8}$ Psychology, Ch. 2, Wallace's translation. 
tion at the same time as they are moved themselves, the assumption here being that the soul is that which supplies animals with motion." "The parallel between soul and fire, which long impressed thought as very rarified matter, brings out very clearly this first effort of thought to connect matter and soul by composing them both of corpuscles and to distinguish them by assigning grosser particles to the one and subtler particles to the other. Some of the Pythagoreans, Aristotle continues, "maintained that the soul was the motes within the air. . . because they present the appearance of continual movement, even though there be a perfect calm."10 There were hints even within early Greek thought of the perplexing necessity, afterward firmly insisted upon by Descartes, to sever the nature of soul or mind from the nature of body and things. Anaxagoras, Aristotle notes, "describes mind as the principle of movement," and some Pythagoreans held that the soul put the "motes within the air" in motion. ${ }^{11}$ The corpuscular view of the soul was already surrounded by suggestions that mind and soul were non-material and outside the world of atoms; but the opinion that mind is subtly corpuscular was a definite mental species in the beginnings of philosophy. Descartes stamped into thinking the distinction between thing and thought as corpuscular and non-corpuscular; but he, apparently, did not preclude a reversion to the older belief. Henslow, quoting Prof. Edgar Lucien Larkin, Director of the Lowe Conservatory in California, through $\mathrm{Mr}$. W. Britton Harvey, describes a startling reversion to the old opinion of Democritus that matter and mind share in a common corpuscular constitution. "When William Crookes made his first experiments with high vacuum tubes, matter put on an entirely new condition. He called it 'radiant matter.' This was in 1879 . The glowing bombarding particles he called 'corpuscles,' others,
- Loc. cit., Ch. 2.
${ }^{10}$ Loc. cit., Ch. 2.
"Loc. cit, Ch. 3. 
'electrons.' But the point is that nothing else, whatever, is in existence. All atoms of matter and of mind are made of corpuscles and these are made of electricity and nothing else. Telepathy consists of a flow of corpuscles away from a mental center and impact on another.... Thoughts are things-currents of real corpuscles.... Our minds, our very thoughts, conscious and subconscious, are flows of corpuscles. Thoughts are as real as these corpuscles."12 Thought seems to have circled back to Democritus-the belief that both mind and matter are corpuscular, and similarly corpuscular, appears to be a cyclic recurrence.

Participation in a common corpuscularity is one concrete expression of community of nature between thoughts and things. Primitive thought began with a general acceptance of this community, or, at least, with a general disability to es cape from it. Australian aborigines still think that they can transfer toothaches to stones and so pass them into other unfortunates who chance to rub against them. The savage cannot realize that dreams are.thoughts in his own mind and not "things" that come to him or to which he goes. A similar tendency to treat thoughts as if they were physical objects, like shoes and ships and sealing-wax, again pervades the thinking of the day. This tendency appears to be a return to an older method of thinking after a period of determined effort to place thoughts and things at opposite poles of being. It had seemed obvious that, though trees and stones and beetles were open to inspection by all, thoughts were privately experienced and privately possessed. They could be communicated, as a writer bares his soul; they could be deduced, as a man reads the face of his friend; they could be known through gesture, cry or speech. But the necessity laid upon men to perfect language for expressing their thoughts to one another seemed to be a necessity because these thoughts belonged exclusively to single

12 Proofs of the Truths of Spiritualism, Ch. 13. 
minds and did not dwell, like sticks and stones, in the open air. Memories of material scenes and things seemed to differ, in their privacy as mental existents, from the scenes and things of which they were memories. A mountain could be seen and remembered by a countless multitude; each member of the multitude had his own memory, independent of the rest, private and inalienable to himself, appearing before his own mind's eye whether others were experiencing it or not and dying with him without prejudice to the memories of others. Thoughts and physical objects seemed to be things apart, these being private processes in single minds, those being out in the open and accessible to all. To-day thoughts are being swept out of their isolation in single minds to keep company with outer things. It may be true that, as James thought, common sense will always contrast and oppose thoughts and things as if they were different sorts of object; it is also true that there is a tendency, too sharply marked to be mistaken, to treat thoughts as if they were things. In the preface to The Candle of Vision, "A. E." speaks of ". . windows in the soul through which can be seen Images created not by human but by the divine imagination." The "Image," the mental picture, because it seems of all thinking most expressly to simulate the thing pictured (a mental picture in memory of a tree seems to be a copy of the real object in a way in which its verbal description is not), is most readily assimilated to the physical object. When A. E. speaks of images in the divine mind as if they were planets created by his hand and, like them, perceptible, he proposes them as candidates for the world of things-he sets thoughts in the same world as physical objects. He does not merely deviate for a moment from the customary opposition between mental images and material things when speaking of the divine mind. The pots we make or the books we read are things, extended in space, alterable in position, changing hands, 
equally perceptible to other eyes and our own. He treats our mental images as if they were companions to these pots and books. "I know," he writes, "that my brain is a court where many living creatures throng"; "I "I was certain that the images which populate the brain have not always been there, nor are refashioned from things seen."14 The image, from being a permanent resident in a single mind and stirred there originally into existence by the action of an external thing, has become a physical thing itself, passing from one mind to another, as a ball may be tossed from one hand to another. "I know that with the pictures of memory mingle pictures which came to us, sometimes from the minds of others, . . . and as meditation grows more exalted, the forms traceable to memory tend to disappear, and we have access to a memory greater than our own, the treasure-house of august memories in the innumerable being of earth." 15 He makes a distinction still between memories in the customary sense, produced in private and experienced in private by a single memorizing mind, and images that lie in earth's treasury, like bullion in a chest, or stored in other minds ready for migration. But a diffusion has begun of memories, of mental images, into the physical world to join the company of things that lie openly without or move from place to place. He speaks of "quickened memories" invading his brain, of the "reperception of an image in memory which is personal to us" as in no way differing "as a psychical act from the perception of images in the memory of earth," of "the ethereal medium which is the keeper of such images," of "pictures of persons or things long past in time" evoked "deliberately out of the memory of nature." "The physical thing continues unchanged by our gaze, as it existed

1s The Candle of Vision, "The Many-coloured Land."

14 Loc. cit., "The Mingling of Natures."

${ }^{10}$ Loc. cit., "The Mystery of Nature."

15 Ibid.

${ }^{17}$ Loc. cit., "The Memory of Earth." 
independently of it before, and it continues when our gaze is removed; the memory picture comes into being as we experience it, it tends to alter as we regard it, and it passes away with the passing of our attention from it-such, at any rate, has been modern belief. A. E. obviously speaks of some memory-images as if they retained their being, as if they migrated, as if they claimed an attention with which they were not simultaneously born: as if, in short, they were things like pebbles or telephone poles. He does not, perhaps, consistently and explicitly refer thoughts and things to a common realm of existence or to a common nature: he has a habit of thinking about images, or thoughts, as if he did so refer them, rather than an explicit adoption of that habit as a settled principle. "Imagination," he observes, "is not a vision of something which already exists, and which in itself must be unchanged by the act of seeing, but by imagination what exists in latency or essence is out-realized and is given a form in thought, and we can contemplate with full consciousness that which hitherto had been unrevealed, or only intuitionally surmised." ${ }^{\prime 18}$ He does, however, steadily tend to diffuse out one class of images into the realm of physical things and to regard them as like in nature to those things. "We must infer," he writes, "when the image is clear and precise, an original of which this is a reflection." ${ }^{\prime 10}$ The relation of physical object and image, Hyacinth's vision of himself in the water, is here applied to relations between an image, conceived as an object, and reflections of itself. "If I am reproached," he writes again, "for the supposition that the soul of earth preserves memory of itself by casting off instant by instant enduring images of its multitudinous life, I am only saying of nature in its fulness what visible nature is doing in its own fashion without cessation." Such enduring images resemble statues which exist at all times 
- whether they are or are not perceived: this curious reversion to the Greek theory of perception, which supposed our mental pictures of objects to be images constantly emitted by them, marks a corresponding reversion to a community of nature between thoughts and things. $\mathrm{He}$ distinguishes the "figures of human memory," accepting them "as being in two dimensions," from the "memory of nature" which "we see in undistorted pictures." In joining the company of physical objects these latter images assume their solidity. They also assume the independence of the perceiving mind which distinguishes the external thing: we must observe whether the horse stands or trots or gallops; we can imagine him as we like, even as breathing fire or swifter than the wind. The figures of imagination, A. E. says, obey his suggestions-they "will walk about with authentic motions and undistorted anatomies." Such "authentic motions and undistorted anatomies," if they are supposed to be reconstructions by the mightiest conscious intellect, involve the intellect in incredulities: these "figures of imagination" are partly independent of the mind which receives them, as the flutter of a flag we have exposed to the wind makes our perceptions follow it and does not follow our perception-they imitate the behavior of real objects so exactly that they must be real objects received by the mind, though obedient to the suggestions of their host. A. E. discovers in his own images a conformity to the "intricate changes" of real objects in real life too miraculously faithful to be the result of his own mind. "I imagine a group of white-robed Arabs standing on a sandy hillock, and they seem of such a noble dignity that I desire to paint them.... I say to myself, 'I wish they would raise their arms above their heads,' and at the suggestion all the figures raise their hands as if in salutation of the dawn... The invention

20 Loc. cit., "Have Imaginations Body?" 
and actual drawing of the intricate pattern of light and shade involved by the lifting of the hands of my imaginary Arabs would be considerable. My brain does not by any swift action foresee in detail the pictorial consequence involved by the lifting of arms, but yet by a single wish, a simple mental suggestion, the intricate changes are made in the figures of imagination as they would be if real Arabs stood before me and raised their hands at my call." Such autonomous images must originate outside himself, thinks A. E., and exist independently of him; their autonomy resembles the autonomy of physical objects which change according to a law and order that is recognized and not imposed by the mind.

This identification of mental image and physical object is no casual vagary of a mind driven by vivid imaginative pictures into a confusion between them and outside things. A. E. has reacted to the stimulus of prevailing tendencies, though his personal psychical outfit may have made him very ready to respond to it. He has followed in his own mystical way the more sober, not to say prosaic, journey of philosophy. For philosophy, after a long effort to restrain mental images from mingling with outward objects, after attempting to deprive them of all qualities permissive of mimicry of the physical thing, after insisting on radical distinctions between non-mental bodies and themselves, is deliberately returning them to the outer reality from which they had been hustled into confinement within the mind. Utterances within the contemplative precincts of the Aristotelian Society outmatch, indeed, the imaginative fervor of A. E. Images, declared Professor Alexander, are external or physical because they have the characteristics of physical objects. This concisely summarizes A. E.'s deduc. tions from his Arabs among the sand hillocks. The image and the percept are the same object in different formsonce more Professor Alexander clinches the adoption of the 
image among physical things. The dream-apparition is physical ${ }^{21}$-again the philosopher is even more emphatic than A. E. who less concisely or unambiguously suggests that "to speak of the moving pictures of the dream as memories or unconscious reconstructions is to speak without subtlety or intellectual comprehension." ${ }^{\prime 22}$ A stroller in the jungle meets a tiger and runs. In the quiet of his tent he sees, in memory, that tiger again and perhaps hears its jaws snap. He meets the same tiger, according to Professor Alexander, though he meets it differently, and he meets it again if he dreams of it by night. The same doctrine, sometimes with less explicitness and often with more reluctance to admit images and physical things from their separate folds in the mental and non-mental worlds into a share of common quality in a common realm, has spread widely through recent thought.

Images, visual images, pictures presented to the nind in memory, reverie and dream, are most easily placed in the same status as physical objects because, of all mental processes, they apparently most resemble them. James asked, more comprehensively, "Are thought and thing as heterogeneous as is commonly said?" With equal comprehensiveness he insists that they are not. "Their rela. tions to time," he affirms, "are identical... . both may be complex or simple. Both are of kinds, can be compared, added and subtracted and arranged in serial order. All sorts of adjectives qualify our thoughts.... they are natural and easy, or laborious. They are beautiful, happy, intense, interesting, wise, idiotic, focal, marginal, useful, confused, vague, precise, rational, casual, general, particular, and many things besides. Moreover, the chapters on 'perception' in the psychology books are full of facts that make for the essential homogeneity of thought with

${ }^{21}$ Proc. Arist. Soc., 1909-10, "On Sensations and Images."

22 The Candle of Vision, "The Architecture of Dream." 
things." ${ }^{23}$ Thought seems to be making a circuit like the sun in his heaven. With a homogeneity of mind and body, of thought and thing, Greek thought began, and to this homogeneity thought seems to have returned.

Yet our mental life impresses us as irreversible. The middle-aged man can no more return to his childhood in mind than he can in body. His eye falls on the old copy of Robinson Crusoe as it lies forgotten on the shelf and he remembers the thrill when he read it as a boy. He takes it down and turns its pages, seeking for the old moment of fresh impression. He cannot recapture it. The old tale touches experiences that were not there to touch in the boy's mind: the old naiveté, the old freshness, the old openness to ideas which were new then and old now, are gone and gone forever. He has gained as well as lost: the tale has still charm, even more charm, but the charm is not the same. He has changed, and changed permanently. In his mental irreversibility he seems to resemble his family descent: his father did not think exactly like his ancestors, he does not think exactly like his father, his son will think differently from him.

Nations seem to resemble families and the whole human race to resemble nations: men seem unable to speak or write or think as they spoke or wrote or thought in the past. How different is the hand-writing in an old commonplace book, picked from its thirty years in the lumber-room, from the hand-writing of to-day! Paleographers tell us that manuscripts are dated by the character of their handwriting, though the dating may require much study to decipher it. Style, too, dates the writer. Writers date themselves by their language, by their vocabulary, by turn of phrase, by texture of thought, by the centers of their interest, by the events they deem possible or impossible, by the allusions they make, by the illustrations they spon

23 Essays in Radical Empiricism, p. 29. 
taneously employ: by the whole nature, character and being of their thought and style. Each age has its own style and its own thought which stamp a date upon its writers. The writers of one epoch differ from one another, as no two peas in a pod are quite alike; but they all cover their writing with the same date, though they write down the same date differently. Any writing separated from us by more than a generation, a page of Scott, a scene from Hamlet, a chapter from Don Quixote or from Homer or from Herodotus, has "belonging to the past" as definitely stamped upon it as a recollection of childhood. It seems impossible to confuse one epoch with another or to suppose that any future epoch will repeat the features of the past. Homer, Plato, Isaiah, Dante, Cervantes, Shakespeare, Goethe, these names seem to represent periods of human thought that are as different from one another as they seem unlikely to recur: mental species that seem as different as the biological species that line the route of evolution. "Belonging to the past" does not, of course, mean "having no present value" nor even "having a value inferior to the present."

Thought may, however, travel in some closed circuits through successive and differing epochs. As the sun travels through the heavens he drags the earth continually through space. Within this path the earth ever circles round the sun: so may there be cycles of thought within the moving route of thought. But perfect cycles of thought, like perfect cosmic recurrences, logically deduced by Nietzsche or implied in early cosmogonies, are probably as abstract and as unrealized conceptions as the perfect circle defined by Euclid. Biology hints to us how to estimate the real significance of such apparent reversions as the resemblance of some speculations to the theories of Democritus, just as she hinted to us that all life, including the mental life which is its flower, is essentially irreversible. Nature does not make new species in the perfect likeness of old species; but 
she does adapt old plans and use them in new contexts. Animal after animal is built on the old four-limb design. There is room for variation: the creature may have four legs, or two legs with two arms, or two legs with two wings, or it may, if it have marine habits, have legs and fins or fins only. Fundamental habits of thought underlie very diverse manifestations, as the four-limb vertebrate design underlies very diverse species of animals. One universal mental habit pervades thought from Democritus and before him, through Descartes and his contemporaries to the philosophy of to-day. The human mind has always formed its concepts on a few primary models of reality. Physical objects, things in space, independent of our thinking, compelling us to conform our thoughts to the order and law of their existence, are, because of the rigorous adjustment to themselves which they exact from us, one of the dominating influences on our lives. We have to think, because our minds are so predominantly adjusted to the external world, in terms of things-things existing in spite of us, singly, permanently, in a way that we have to learn and can only imperfectly control. However we endeavor to restrict thoughts to purely mental existence, however we endeavor to deprive them of the properties characteristic of physical objects, we cannot think right away from the habit of thought imposed upon us by the external world. We think of ourselves as spectators of independent things outside us and as co-actors with them on the stage with which they provide us. Our conception of ourselves and our thoughts is habitually formed upon this primary model of reality. The internal, private world of the mind, whatever our insistence on the absoluteness of the distinction between the mental and the nonmental, is an image of the spectator and his outside world, of the organism and its physical environment. We regard our thoughts as objects surrounding our ego because we 
regard physical things as objects surrounding our whole persons. As we perceive and deal with our surroundings, so we are compelled to think of our minds or egos as ex.. periencing and dealing with thoughts, ideas or images which form the contents of their inner, mental worlds. We are inveterate mental modelers on the type of reality provided by the spectator and his material world. This habit may be repressed, almost perhaps to apparent nothingness, as the four-limb mammalian design shrinks from notice in the whale. But it is always there and from time to tine. it becomes insistent. The electrons which some now sup. pose to compose both the mental and non-mental, both the physical and the psychical, are not the spherical atoms of Democritus. Thought has neither returned upon itself nor reversed its course to move backward. The modern neo-realistic equivalence between image and physical object is not a restoration of Greek notions of perception or imagination. There has been a fresh insistence by a permanent habit of thought. The common-sense opposition between thought and thing, affirmed by James, has never transcended the fundamental model of reality provided by the physical object. Thoughts have always been finally conceived after the manner of things, however scrupulously they have been distinguished from them. The electrontheory of the soul, the reduction by $\mathrm{A}$. E. and by the neorealists of mental images to a physical variety of status, James's drastic homogenization of thoughts and things, all these are extra insistences by a permanent mental habit, which continues to impress upon the human mind a permanent bias, of thinking of the mental in terms of the physical. Fate seems to have decreed that, in the last resort, mental images and statues shall inhabit the same world.

BradFord, ENGLAND. 